\title{
Hospital response to a chemical incident: report on casualties of an ethyldichlorosilane spill
}

\author{
T Thanabalasingham, M W Beckett, V Murray
}

Medical management of chemical incidents needs communication between emergency services, hospitals, and poisons centres
Accident and Emergency Department, West Middlesex University Hospital, Isleworth, Middlesex

T Thanabalasingham, MRCP, registrar

M W Beckett, MRCP,

consultant in charge

National Poisons Unit, Guy's Hospital, London SE1 9RT

V Murray, MFOM, honorary consultant occupational toxicologist

Correspondence to: Dr Murray.

BMf 1991;302:101-2

Even though large chemical spills and the release of toxic chemicals are rarely reported, ${ }^{1}$ their management requires the preparation of a coordinated response rather than the regrets of hindsight. We report a spill of ethyldichlorosilane for two reasons: firstly, ethyldichlorosilane is highly corrosive and a spill of it has not to our knowledge been reported previously, and secondly, the incident illustrates the need for close coordination of all those participating in its management.

\section{Incident report}

At 1346 on 27 June 1990 the police were notified that a flatbacked lorry carrying two containers of chemicals had been abandoned on the A4, a main arterial road in London. Two officers arrived by car at 1347 and noticed that a chemical spill was causing bubbling and damage to the road surface. They had problems in identifying the chemical substance concerned because they could not find the lorry driver and found more transport emergency cards in the lorry driver's cab than the number of chemicals on the lorry. (Transport emergency cards are part of a voluntary, non-mandatory system to provide detailed information carried for emergency service use on chemicals carried. ${ }^{2}$ )

The fire brigade arrived at 1348 , having been called by the lorry driver at 1345 . In collaboration with their chemical control unit, the fire officers were able to identify the substance concerned from the information given by the lorry driver. They applied their standard procedures for managing a chemical spill, closing the road and advising their staff on relevant protective clothing (chemical protection suit and breathing apparatus). They continued to work on the incident, including coordinating environmental control, transferring the remaining chemicals from the lorry, and clearing debris, until the road was reopened at 2025 .

The police, who were responsible for traffic control, worked without protective clothing as the substance and its toxicity were apparently not known to them until 1418, by which time the officers had been exposed for some time.

The two police officers who had first arrived at the

TABLE I-Details of patients exposed to ethyldichlorosilane

\begin{tabular}{|c|c|c|c|c|c|c|c|c|}
\hline \multirow[b]{2}{*}{ Case No } & \multirow[b]{2}{*}{$\begin{array}{c}\text { Age } \\
\text { (years) }\end{array}$} & \multirow[b]{2}{*}{ Sex } & \multirow[b]{2}{*}{ Occupation } & \multicolumn{2}{|c|}{ At scene } & \multirow[b]{2}{*}{$\begin{array}{c}\text { Time of } \\
\text { arrival at } \\
\text { hospital }\end{array}$} & \multirow[b]{2}{*}{ Admitted } & \multirow[b]{2}{*}{$\begin{array}{l}\text { Duration of } \\
\text { symptoms } \\
\text { (days) }\end{array}$} \\
\hline & & & & $\begin{array}{c}\text { Time } \\
\text { of } \\
\text { arrival }\end{array}$ & $\begin{array}{c}\text { Distance } \\
\text { downwind } \\
(\mathrm{m})\end{array}$ & & & \\
\hline 1 & 26 & $M$ & Police & 1347 & 0 & 1450 & Yes & 5 \\
\hline 2 & 29 & $M$ & Police & 1347 & 0 & 1450 & No & 1 \\
\hline 3 & 27 & $M$ & Police & 1400 & 35 & 1455 & No & 4 \\
\hline 4 & 31 & $M$ & Police & 1415 & 150 & 1550 & Yes & 5 \\
\hline 5 & 45 & $M$ & Ambulanceman & 1530 & 150 & 1550 & No & 1 \\
\hline 6 & 23 & $M$ & Police & 1400 & 100 & 1600 & No & 1 \\
\hline 7 & 48 & $M$ & Police & 1400 & 100 & 1600 & No & 1 \\
\hline 8 & 22 & $\mathrm{~F}$ & Police & 1400 & 200 & 1600 & Yes & 4 \\
\hline 9 & 24 & $M$ & Police & 1415 & 35 & 1610 & No & 1 \\
\hline 10 & 26 & $M$ & Police & 1400 & 150 & 1610 & No & 3 \\
\hline 11 & 48 & $\mathrm{~F}$ & Bystander & 1400 & 300 & 1901 & No & 1 \\
\hline 12 & 22 & $\mathrm{~F}$ & Police & 1400 & 300 & 2030 & No & 2 \\
\hline
\end{tabular}

scene became ill and were taken to West Middlesex University Hospital, arriving at 1450 at the accident and emergency department, which had not been informed about the incident before their arrival. Indeed, the severity of the incident was appreciated at the hospital only when another police officer was admitted at 1520 . He had arrived at the scene at 1415 and had stood about $150 \mathrm{~m}$ downwind; at about 1515 he had been found unconscious in the road. He had recovered consciousness, however, by the time he reached hospital.

In total, 10 police officers, one ambulanceman, and one lay bystander were taken to West Middlesex Hospital during the afternoon. Summary information on the approximate time of exposure, distance from the lorry, time of arrival, and duration of symptoms is given in table I. The two patients with the most serious symptoms had dyspnoea with wheezing. All 12 reported a burning sensation in the throat; 10 had eye irritation and six skin irritation. Other symptoms included malaise (six), dizziness (five), and headache (four).

The National Poisons Unit was contacted initially at 1500 by the hospital and requested to identify the substance and to provide information and advice on management. Within 15 minutes the chemical was identified from the information on the container label as ethyldichlorosilane. It, like other chlorosilanes, is highly corrosive, reacting violently with water to form hydrochloric acid and polysiloxane condensation products. ${ }^{3}$ Although comparatively little is known about the consequences for people of acute exposure, VM initially gave advice on decontamination and general supportive care. As the incident developed over the next few hours she discussed the consequences for health care.

All patients were decontaminated by stripping off their clothes and showering. The limited facilities in the accident and emergency department (two staff showers only) meant, however, that most patients were delayed in washing off the chemical. Three patients required a full eye wash with normal saline irrigation for 15 minutes. Serial peak expiratory flow readings with a Wright's peak flow meter were obtained in 10 patients. Four patients showed a greater than $15 \%$ reduction in peak expiratory flow (range $20-23 \%$ ) in comparison with follow up values (table II), indicating appreciable temporary bronchoconstriction secondary to exposure to ethyldichlorosilane. The three patients with the most severe symptoms were admitted for overnight observation (table I) and were discharged the following day. The nine other patients were discharged after three hours of observation.

As the patients were not decontaminated until 1515,25 minutes or so after the first group of three patients had arrived, the registrar and staff nurse responsible for initial assessment and coordination were exposed to ethyldichlorosilane from the casualties. Within five hours they also developed minor symptoms of burning sensation in the throat and eye irritation, which did not need any treatment. Chemical protective 
TABLE II-Peak expiratory flow readings in patients exposed to ethyldichlorosilane

\begin{tabular}{|c|c|c|c|c|c|}
\hline \multirow[b]{2}{*}{ Case No } & \multirow{2}{*}{$\begin{array}{c}\text { Age } \\
\text { (years) }\end{array}$} & \multirow[b]{2}{*}{ Sex } & \multicolumn{2}{|c|}{$\begin{array}{l}\text { Peak expiratory flow reading } \\
\qquad(1 / \mathrm{min})\end{array}$} & \multirow[b]{2}{*}{$\%$ Change } \\
\hline & & & On arrival & At follow up & \\
\hline 1 & 26 & $M$ & 500 & 620 & 20 \\
\hline 2 & 29 & $M$ & 580 & 640 & 10 \\
\hline 3 & 27 & $M$ & 650 & 640 & -2 \\
\hline 4 & 31 & $M$ & 520 & 670 & 23 \\
\hline 5 & 45 & $M$ & 600 & 640 & 6 \\
\hline 6 & 23 & $M$ & 540 & 700 & 23 \\
\hline 7 & 48 & $M$ & 560 & 630 & 11 \\
\hline 8 & 22 & $\mathrm{~F}$ & 440 & 550 & 20 \\
\hline 9 & 24 & $M$ & 720 & 700 & -3 \\
\hline 10 & 26 & $M$ & 540 & 600 & 10 \\
\hline 11 & 48 & $\mathrm{~F}$ & ND & ND & \\
\hline 12 & 22 & $\mathrm{~F}$ & ND & ND & \\
\hline
\end{tabular}

$\mathrm{ND}=$ Not done.

clothing was not used by staff while examining patients as it was not available at the hospital.

At follow up two to three weeks later one of us (TT) found that symptoms had persisted in all patients for one to five days after exposure. Most patients had experienced headache, dizziness, and malaise. The two patients admitted with respiratory symptoms had continued to have shortness of breath, but the most severely affected patient also complained of wheezing and generalised dermatitis lasting for five days. Two of the police officers had returned to work the following day, seven after five days, and the one most seriously affected after six days. The ambulanceman and the bystander had returned to work the following day. On examination at follow up the patients reported only minimal residual effects remaining, and peak flows returned to those predicted by age, height, and sex.

\section{Comment}

The potential for a minor incident to escalate into a major incident should not be forgotten. Major chemical disasters from inhalation of toxic substances, such as in Seveso, ${ }^{4}$ Bhopal, ${ }^{5}$ and the Cameroons, ${ }^{6}$ have been reported, but only a few reports of the effective management of minor incidents have been published. ${ }^{78}$ In the management of this comparatively small incident, however, several problems occurred, both inside and outside the hospital, and these provide lessons that can be used to improve effective planning for any future incident.

- The failure in communication between the police, fire brigade, and ambulance and hospital services, particularly about the identification of the chemical substance and its toxicity, exemplifies the concern about communication between professional groups involved in the medical aspects of management of chemical incidents. This concern was expressed at a multidisciplinary meeting at the Royal Society of Medicine on medical aspects of managing major chemical disasters ${ }^{9}$

- Protective clothing is provided rarely for staff in accident and emergency departments ${ }^{10}$ and is not provided for the police

- The accident and emergency department (in common with many other such departments) did not have effective decontamination facilities available, and those that were available did not comply with those recommended by hospital building regulations (Note 22, 1986).

In addition, though the National Poisons Unit was able to provide help, because it was not notified by the emergency services it could not prepare information in advance of the patients' arrival at hospital.

Review of this incident has increased our concern that if the incident had incurred more casualties the accident and emergency department would have had great difficulty in providing decontamination and other facilities. We believe that such departments need protocols for managing large numbers of casualties exposed to chemicals, particularly when they arrive without warning. Furthermore, our report shows that the potential toxicity of volatile chemicals needs to be more widely appreciated, and it highlights the need for better communication and closer coordination between emergency and medical services.

1 Canadine IC. The possibility of major incidents in chemical distribution. In: Murray V, ed. Major chemical disasters: medical aspects of management. London: Royal Society of Medicine, 1990:33-9. (International Congress and Symposium Series 155 .

2 Jerrom DA. The fire brigade, the first response. In: Murray V, ed. Major chemical disasters: medical aspects of management. London: Royal Society of Medicine, 1990:51-78. (International Congress and Symposium Series 155.)

3 Rowe VK, Spencer HC, Bass SL. Toxicological studies on certain commercial silanes and hydrolyzable silane intermediates. Fournal of Industrial Hygiene 1948;30:332-52.

4 Centers for Disease Control. Preliminary report: 2,3,7,8-tetrachlorodibenzop-dioxin. Exposure to humans-Seveso, Italy. MMWR 1988;37:733-6.

5 International Confederation of Free Trade Unions and International Federation of Chemical, Energy and General Workers' Union. Trade union report on Bhopal. Geneva: ICFTU and ICEF, 1985 .

6 Baxter PJ, Kapila M, Mfonfu D. Lake Nyos disaster, Cameroon, 1986: the medical effects of large scale emission of carbon dioxide? BMJ 1989;298: medical

7 Sach $M$, Reichi $M$, Sleet RA. Handling of mass casualties following toxic fume inhalation. British fournal of Accident and Emergency Medicine 1988;3:9-10.

8 Tong TG. Problems relating to major chemical disasters: diagnosis and risk Tong TG. Problems relating to major chemical disasters: diagnosis and risk
assessment. In: Murray V, ed. Major chemical disasters: medical aspects of management. London: Royal Society of Medicine, 1990:141-8. (International Congress and Symposium Series 155 .

9 Taylor D, Murray VSG, Philipp R, Gilbert M. Conclusions and recommendations. In: Murray V, ed. Major chemical disasters: medical aspects of management. London: Royal Society of Medicine, 1990:203-4. (International Congress and Symposium Series 155.

10 Dallos V. Immediate response: accident and emergency departments. In Murray V, ed. Major chemical disasters: medical aspects of management London: Royal Society of Medicine, 1990:73-8. (International Congress and Symposium Series 155 .)

(Accepted 13 November 1990 significant percentage of patients. The data showed that a single smear with squamous atypia in patients over 50 years of age was associated with cervical intraepithelial neoplasia, human papilloma virus, or vaginal intraepithelial neoplasia in fewer than $5 \%$ of the patients. In addition,

abnormal results of repeat cytology had a significantly lower likelihood of being associated with significant disease when compared with similar data from younger patients. Despite this, however, Kaminski et al thought that a report of squamous atypia on the smears should not be considered normal and that further evaluation was required. They also pointed out that a low prevalence of significant cervical intraepithelial neoplasia observed among the older women in their series may reflect a lower incidence of risk factors that prevailed 20 to 30 years ago. Their results, therefore, should not be extrapolated to alter the current surveillance protocols. $-P$ B TERRY, consultant obstetrician and gynaecologist, Aberdeen

I Kaminski PF, Sorosky JI, Wheelock JB, Stevens CW Jr. The significance of atypical cervica cytology in an older population. Obstet Gynecol 1989;73:13-5. 